\title{
Nonmetal and No Diameter Damage Borehole Wall Strengthening Technology
}

\author{
Lu Chunhua ${ }^{1}$, Jiang Guosheng ${ }^{1}$, Zhang Tao ${ }^{1}$ \& Fan Jiaxing ${ }^{1}$ \\ ${ }^{1}$ Engineering Faculty, China University of Geosciences, Wuhan, China \\ Correspondence: Lu Chunhua, Engineering Faculty, China University of Geosciences, No. 388 Lumo Road, \\ Wuhan, China. Tel: 86-27-8748-1030. E-mail: cuglch@yahoo.cn
}

Received: June 14, 2012 Accepted: June 28, 2012 Online Published: July 30, 2012

doi:10.5539/esr.v1n2p291 URL: http://dx.doi.org/10.5539/esr.v1n2p291

\begin{abstract}
Instability of borehole wall is a common phenomenon when drilling in complex strata, which bring great difficulties to drilling. Traditional way of casing pipe can isolate unstable borehole wall reliably, however, there are some shortcomings: for example, reducing hole-diameter etc. In order to seek a simple, effective and no diameter damage way for supporting collapsed well section, the project team devotes to research hot-melt way used in dry hole and polyurethane way used in hole with water. The paper elaborates process principle and indoor tests of the two ways in detail. Study indicate, the two kinds of nonmetal borehole wall strengthening technology have many advantages, like simple to operate, effect is significant and no diameter to diameter of borehole, which have certain application prospect.
\end{abstract}

Keywords: borehole wall strengthening, hot-metal way, polyurethane

\section{Introduction}

When drilling, maintaining the stability of the sidewall is one of the basic conditions to ensure normal drilling. The collapses of sidewall can result in burying drilling tools, delaying construction period and even abandoning the borehole, which will make a huge economic loss (Shi \& Liu, 2004; Peng \& Dou, 2010). However, the sidewall instability is a prevalent technical challenge in the process of drilling and has been plagued for a long time (Chen, 1981; Yang \& Su, 2008). For minor collapse in the drilling process, generally through using the high quality mud won't cause difficulties to drilling, but if drilling in broken and collapsed formation, in the short term, the sidewall will form a large-scale collapse and this situation is usually dealt with by supporting technologies of casing etc (Du \& Hu, 1992; Chen \& Sun, 2008). This paper will introduce two kinds of nonmetal sidewall strengthening technologies which have many advantages, like simple to operate, effect is significant and no damage to diameter of borehole.

\section{Hot-melt Process Principle of Supporting the Sidewall}

The basic principle of hot-melt method to reinforce the hole wall is shown in Figure 1, in the figure, 1 is to be reinforced sidewall, 2 is hot-melt granular materials, 3 is heating unit and 4 is reinforced sidewall. The heating element 3 produces a lot of heat and lifts slowly along the arrow of diagram, when encountering with the heating element, the hot-melt granular materials 2 (or hot melt pipe) will melt or soften quickly, and then part of the material will be squeezed into the cracks of sidewall to bond the broken rock together as a whole, in addition, the other part of the material will form casing support in the sidewall, so as to achieve the purpose of reinforcing sidewall.

The hot-melt method to reinforce sidewall can be divided into three processes: melting or softening, extrusion molding, cooling and solidifying.

1) Melting or softening: Through the heating element to produce a certain amount of heat to the melting point or softening point of the material, so make it in flow or semi-fluid state. For hot melt pipes, they will reach the softening state. For hot-melt granular materials, they will melt, reaching a flow or semi-fluid state.

2) Extrusion molding: After melting or softening material, in the extrusion of the heating element, part of the fluid material will be squeezed into the rock fractures to bond the broken rocks together, another part of the material is continuously adhere to the borewall to form the casing in order to achieve the purpose of supporting sidewall. 
3) Cooling and solidifying: After molding, the physical and mechanical properties of the material only within a certain temperature range will be showed. After the extrusion stage, the material must have been solidified for a short time will reach a certain strength is qualified for the role of supporting and strengthening the sidewall.

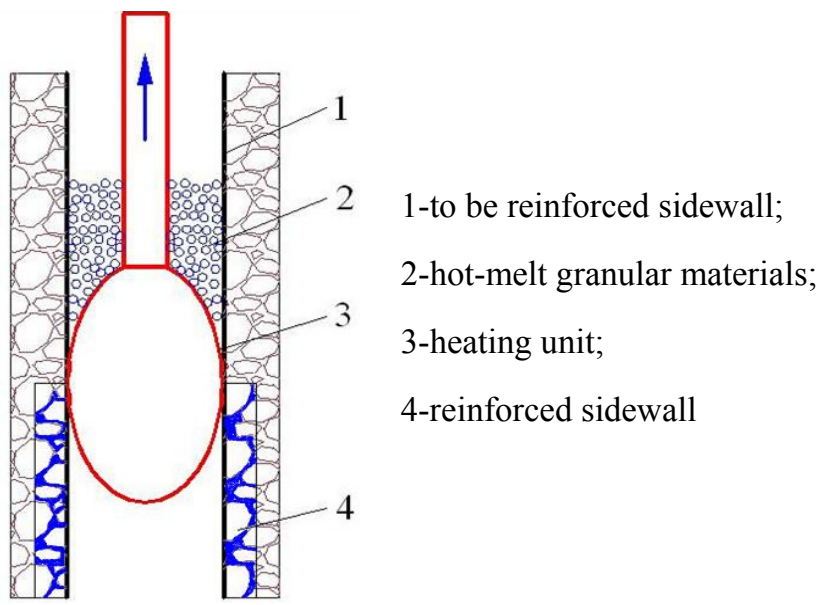

Figure 1. Hot-melt process principle of supporting the sidewall

\section{Experiment of Hot-melt to Support Sidewall}

After plenty of investigation and testing the properties of the material, the project team confirm two granular materials which are suitable for hot-melt sidewall reinforcement. The materials are TPU (Thermoplastic polyurethanes) hot melt adhesive and EVA (ethylene-vinyl acetate copo) hot melt adhesive.

TPU is a kind of hot plastic polyurethane adhesive, have excellent rubber characteristic, can adapt to different thermal expansion coefficient of adhesion base material, it has formed between the base material soft-hard transition layer, not only stick relay is strong, also excellent buffering, shock absorption function, have excellent flexibility characteristics, shear strength and impact resistance characteristics, it is suitable for various structural bonding field ( $\mathrm{Liu} \& \mathrm{Wu}, 2008$; $\mathrm{Liu} \& \mathrm{Li}, 2010$ ). Its shape is granular, particle size is $\Phi 2-3 \mathrm{~mm}$, basic performance parameters of the material is shown in Table 1.

Table 1. Basic performance parameters of TPU hot-melt adhesive

\begin{tabular}{cccccc}
\hline & $\begin{array}{c}\text { Melting temperature } \\
\text { range } \\
\text { Product name }\end{array}$ & $\begin{array}{c}\text { Molten index } \\
\mathrm{g} / 10 \min @ 160^{\circ} \mathrm{C}\end{array}$ & $\begin{array}{c}\text { Viscosity } \\
\text { Pa.s } @ 160^{\circ} \mathrm{C}\end{array}$ & $\begin{array}{c}\text { Thermal bonding } \\
\text { temperature } \\
{ }^{\circ} \mathrm{C}\end{array}$ & $\begin{array}{c}\text { Thermal bonding } \\
\text { pressure } \\
\mathrm{kg} / \mathrm{cm}^{2}\end{array}$ \\
\hline TPU & $95-115$ & 50 & 300 & $135-150$ & $0.2-0.5$ \\
\hline
\end{tabular}

EVA is a kind of translucent to opaque white wax-like material, soft and elastic rubber, can lengthen, non-toxic, tasteless. Cohesion of EVA is strong, melting surface tension is small. EVA can adhere to almost all materials, which have many advantages, like high solidifying speed, solified body with high strength and toughness. The basic properties parameters of the EVA in Table 2.

Table 2. Basic performance parameters of EVA hot-melt adhesive

\begin{tabular}{cccccc}
\hline $\begin{array}{c}\text { Product } \\
\text { name }\end{array}$ & $\begin{array}{c}\text { Melting temperature } \\
\text { range } \\
{ }^{\circ} \mathrm{C}\end{array}$ & $\begin{array}{c}\text { Molten index } \\
\mathrm{g} / 10 \text { min } \\
@ 160^{\circ} \mathrm{C}\end{array}$ & $\begin{array}{c}\text { Viscosity } \\
\text { Pa.s } \\
@ 160^{\circ} \mathrm{C}\end{array}$ & $\begin{array}{c}\text { Thermal bonding } \\
\text { temperature } \\
{ }^{\circ} \mathrm{C}\end{array}$ & $\begin{array}{c}\text { Thermal bonding } \\
\text { pressure } \\
\mathrm{kg} / \mathrm{cm}^{2}\end{array}$ \\
\hline EVA & $75-90$ & 150 & 180 & $90-120$ & $0.1-1.5$ \\
\hline
\end{tabular}


At the same time, carry out the indoor experiment, to simulate the sidewall, the project team designs the sidewall simulator as the Figure 2. The main part of the device was made of one cylinder, and the cylinder was cut open symmetry in axial. Outside of the main subject is equipped with the lathedog and the landing leg, in the bottom was equipped with the end cover. The landing leg is fixed with the ground through the rivet. The cylinder is perpendicular to the ground.

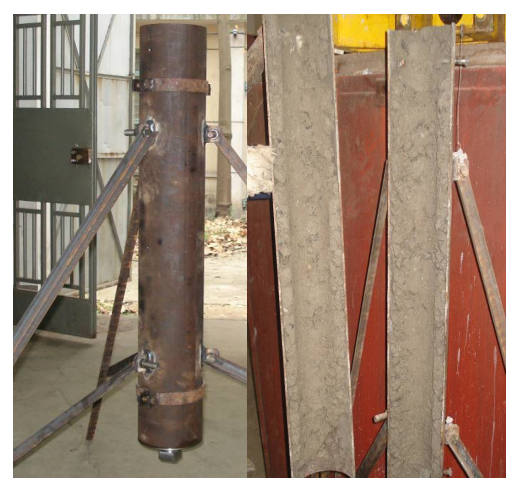

Figure 2. Sidewall simulator

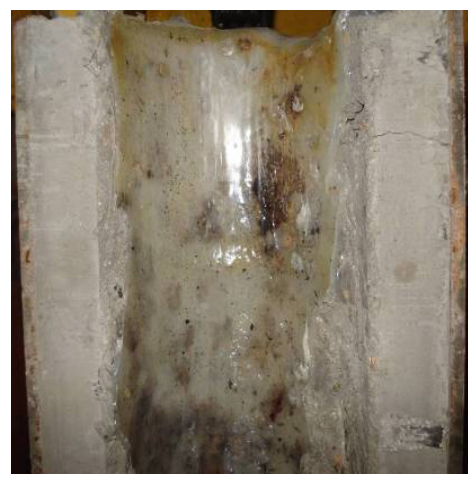

Figure 3. The reinforcement sidewall effect by the EVA hot melt adhesive

When carry out the experiment, first to put another cylinder into the inner cylinder, then put some small stones or other materials into the clearance between the inside cylinder and the outside cylinder in order to simulate the different cranny sidewall. Connect the heat device well, operate the power head rig, at the meanwhile make the heat unit lie in the bottom of the artificial sidewall. Connect the electric power source of the heat device. Adjust the power to the proper quantity, and monitor the surface temperature of the heat unit constantly. When the temperature reach to the proper quantity, put the hot melt materials from the artificial wellhead. Operate the rig and make the heat unit move up slowly and with uniform velocity. Cooling and moldng in a short time, then open the simulating sidewall, observe and detect the reinforcement effect of the sidewall (Tan \& Dai, 2006; Sun, Wu, \& Tang, 2005).

The project team carried out plenty of experiments. Find out the reinforcing effects of the EVA and the TPU granular hot melt material good, especially the effect of the mixture of the two is the best.

The sidewall reinforcing effect of the EVA hot melt adhesive is showed as the Figure 3 . This material have many advantages, such as low melting point, high speed molding, bonding with the sidewall firmly, after melting the material can be permeate into the fracture of the sidewall, formed pipe shape is regular. The disadvantage is that the material has a certain brittle after cooling and molding.

The characteristic of hole wall reinforcement by TPU hot melt adhesive is as follows: formed relatively complete casing pipe, granule melting completely, part of the molten hot melt adhesive can be well squeezed into the hole wall cracks and cemented, having nice toughness after Cooling molding but the hardness not as well as EVA hot melt adhesive.

Considering the advantages and disadvantages of EVA and TPU hot melt adhesive, mixed granular materials of EVA and TPU can obtain desired reinforcement effect: relatively high toughness and strength, part of the hot melt adhesive squeezed into the hole wall cracks and strongly cemented, then forming relatively complete casing pipe.

\section{Process Principle of Polyurethane Reinforcing Borehole Wall}

Polyurethane is a kind of synthetic polymer plugging material through polyisocyanate polyether polyol, which is commonly known as swelling rubber. The material can react with water and form consolidation body. It has the advantages of high molding strength, high curing speed, high chemical stability of consolidation body, adjustable molding speed, non-toxic and no pollution to environment, etc. The process principle of polyurethane reinforcing borehole wall is shown in Figure 4.

When strata need to be reinforced, take irrigator down into required reinforcing borehole section. The irrigator is full of liquid polyurethane. Once liquid polyurethane squeezed out of irrigator, it reacts violently with water in the hole. The volume rapidly expand and full of the hole section, and squeeze into hole wall cracks. The material 
can achieve high consolidation strength in a short period of time. Then take sweep hole drilling with the same diameter drill bit.

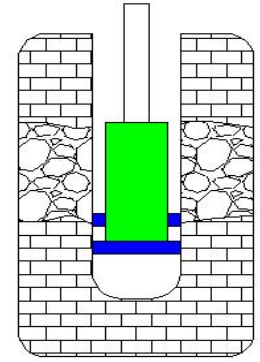

Puting irrigator into borehole section need to be reinforced

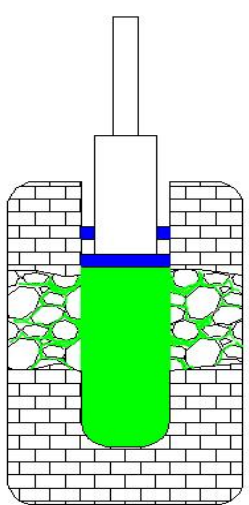

Polyurethane reacts with water and be squeezed into hole wall cracks

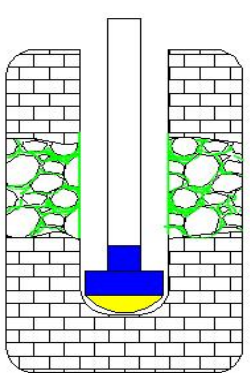

Taking sweep hole drilling with the same diameter bit

Figure 4. Schematic diagram of reinforcing borehole wall with polyurethane

\section{Laboratory Test of Reinforcing Borehole Wall}

\subsection{Test 1: Seal Reinforcement Test}

Test Method: taking a certain amount of gravel into the container, adding water until submerging gravel, then adding the liquid polyurethane material, sealing the container and observing experimental phenomenon.

Test Results: the reaction of polyurethane with water is violent. The multiple of material expansion is limited to about 3 times. The bond between gravel and polyurethane is strong. The consolidation body is relatively dense and itself has high strength. The result is as shown in Figure 5.

In addition, the team carried out several tests in the case of different multiples of material expansion. The result shows that with smaller multiples of polyurethane expansion, the consolidation body has higher strength and bond. With multiple of polyurethane expansion increasing, bond strength between polyurethane and gravel reduce. Therefore, it is essential to choose a reasonable multiple of polyurethane expansion. Through experiments can learn that when the multiple of polyurethane expansion is more than 10 times, the strength of cemented body reduce significantly. When the multiple of polyurethane expansion is 5 times, its strength and the other parameters are reasonable. Therefore recommend choosing multiple of polyurethane expansion at about five times in actual reinforcing borehole wall.

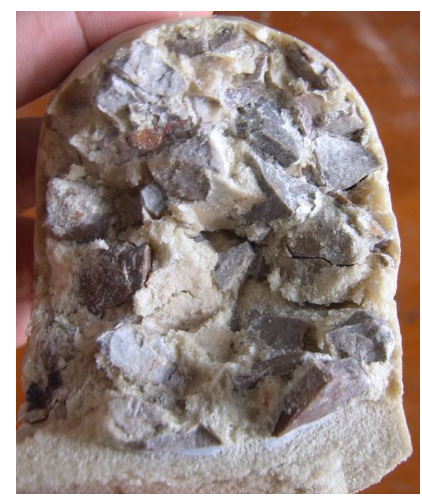

Figure 5. Formed concretion body of polyurethane and water

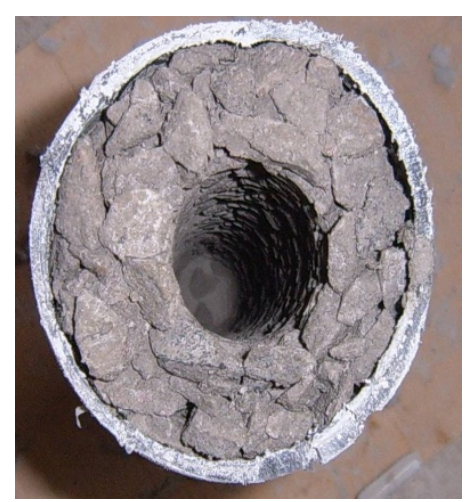

Figure 6. The artificial simulation sidewall which is made of the small stones 


\subsection{Test 2: Reinforcement Tests of Artificial Simulation Sidewall}

Test method: Using the small stones to make the artificial simulation sidewall that is showed as the Fig 6 , and the inner diameter of the artificial simulation sidewall is $30 \mathrm{~mm}$, the wall thickness is $25 \mathrm{~mm}$, the porosity is about $30 \%$ and the length of sidewall is $100 \mathrm{~mm}$. First fill up with water in the artificial simulation sidewall, then add $400 \mathrm{ml}$ liquid polyurethane, and take seal measures in the orifice, in the meantime control the expansion multiple of the polyurethane in about 5 times, watched experiment phenomenon.

Test results: After testing, the reinforcement effect of the artificial simulation sidewall is shown as the Fig 7 , from which we can see the inner hole is full of the concretion that is generated by the chemical reaction between polyurethane and water. Meanwhile, under the inflation pressure, some concretion permeate into the gap of the artificial simulation sidewall, these concretions make the artificial simulation bond firmly into a whole, in a word the reinforcement effect of the sidewall is remarkable.

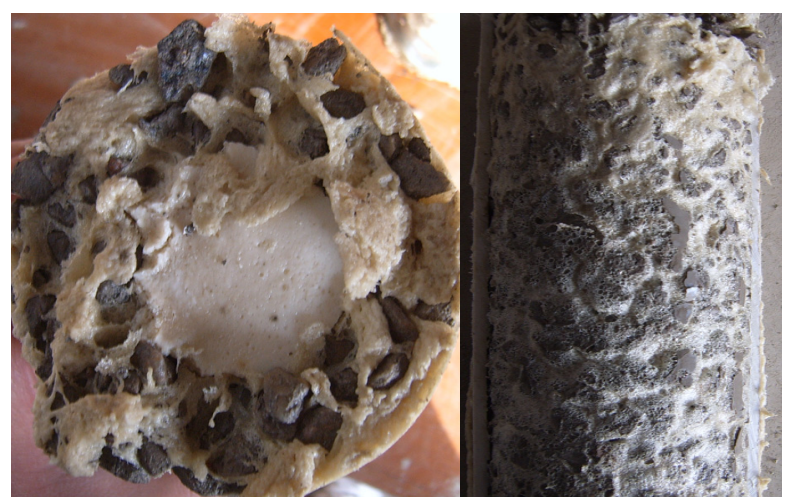

Figure 7. the reinforcement effect of the artificial simulation sidewall

\section{Discussion}

1) The Melt method is a new technology that is used to reinforce the sidewall by bonding the broken rock mass. Firstly, heating up the hot melt materials which are granular till melting down by the heating unit, then push the melted materials in the sidewall fracture. The process principle and the traditional sidewall reinforcement technique are completely different. It mainly used in the dry hole, and the key techniques are the properties of the hot melt materials and the design of the high power heating unit.

2) The method of the polyurethane supporting sidewall is using the properties that the polyurethane will solidify quickly after the chemical react with water. In the process of expanding, the polyurethane permeates into the sidewall fracture. After solidifying, the whole sidewall that is rupture and easy slump will bond firmly into a whole. Finally achieve the purpose of supporting sidewall. The method is mainly used in the hole with water, the key techniques is to control the distension rate and solidifying speed of polyurethane. The test shows that when the distension rate of the polyurethane is under the control of about 5 times, all of the technical indicators are good.

3) Compared with the traditional way of casing sidewall supporting, the hot melt method and the polyurethane sidewall reinforcement technology have many advantages, such as simple operation, low cost, at the same time not reduce the hole diameter etc.With the mineral exploration turn to the deep, when we drill the complex stratum, the problems that the sidewall destabilization will more and more. The nonmetal sidewall reinforcement technology provides a new choice, and it has a certain application prospect.

\section{Acknowledgements}

This research was supported by special funds used for central university basic scientific research and dig and drill research center of ministry of education, thank all person offer help to the project research.

\section{References}

Chen, J., \& Sun, L. (2008). Techonlogy of well cementing with expandable tube and its application. Exploration engineering, 8, 19-21.

Chen, Z. C. (1981). Situation and prospect of supporting the hole walls and plugging the leaky zone with cement. 
Du, H., \& Hu, Z. Y. (1992). Practice and discussion on supporting the hole walls and plugging the leaky zone with common portland cement. Coal Geology \& Exploration, 20(2), 63-65.

Liu, C. L., \& Wu, D. (2008). Study on Toughening of POM by TPU. Polyurethane industry, 23(4), 12-15.

Liu, C., \& Li, X. L. (2010). The modification of polyurethanefoam in coal mine. Coal mine safety, 426, 10-12.

Peng, Z. M., \& Dou, S. B. (2010). Commentary development status of expandable casing technology at home and aboard. Jointing pipe, 33(6), 5-9.

Shi, D. Q., \& Liu, G. (2004). Research and treatment of borehole walls' collapse and landslide accidents. West-china Exploration Engineering, 7, 124-25.

Sun, R. M., Wu, L. J., \& Tang, F. L. (2005). Experimental research on hot melt drilling technology. Geological Science and Technology Information, 24(7), 23-26.

Tan, L. H., \& Dai, Y. M. (2006). Progress in study on the reinforced rigid polyurethane. Materials Review, 9 , 21-24.

Yang, Z. J., \& Su, C. M. (2008). Advances in sidewall strengthening technology. Fault-block oil \& gas field, $15(3), 99-102$. 